\section{Hew from the}

Naterials

Pesearch

Society

Workshop Series

\section{Plan now to attend these 1999 Workshops}

\section{TRIBOLOGY OH THE 30Oth AHHIUERSARY OF AMONTON'S LAW}

\author{
June 20-22, 1999 \\ Fairmont Hotel \\ San Jose, CA
}

\section{AOUAHCES IH THHW-FILM SIMULATIOHS AHD EYPEAMMEHTRL UEAFFICATIOH}

\author{
June 23-25, 1999 \\ Fairmont Hotel \\ San Jose, CA
}

\section{Register by June 1 to take aduantage of preregistration fees.}

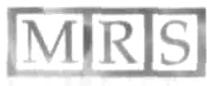

The deadline for contributed papers to Workshop Organizers is April 15 (mail submissions) and April $\mathbf{3 0}$ (e-mail submisssions).

For complete details, see:

http://www.mrs.org/meetings/workshop99/

\section{Positions Available}

\section{FACULTY POSITION \\ Department of Materials Science and Engineering University of Virginia}

The Department of Materials Science and Engineering at the University of Virginia invites applications for a tenure-track position at the Assistant Professor level in the field of electronic materials. Candidates should possess a doctoral degree in a relevant discipline, and should demonstrate the potential for an internationally recognized research program and for teaching excellence at undergraduate and graduate levels. In addition, we seek candidates who can demonstrate the ability to build bridges between different academic disciplines. Applications from women and minority candidates are particularly encouraged.

The Department of Materials Science and Engineering is a highly ranked program, with approximately 20 faculty and 80 graduate students and internationally recognized research programs spanning a broad range of materials. Facilities available within the MSE department, or through collaboration with other departments in the School of Engineering and Applied Science include: State-of-theart electron microscopes, a $\mathrm{Ga}^{+}$focused ion beam, a range of materials deposition systems (MBE, PVD, CVD), electronic materials processing ( 3500 square feet of cleanroom space), surface analysis techniques (Auger, XPS, ion scattering), scanning probe microscopes, and $x$-ray diffraction.

Two major semiconductor manufacturing facilities have been sited within the Commonwealth of Virginia, further raising importance, visibility, and funding opportunities for the broad field of microelectronics at the Department, School, University, and State levels. Opportunities for industrial collaborations and interdisciplinary research are excellent.

Please send a letter of application with a current resume, statement of research interests, summary of research career and teaching experience to date, and the names of five references familiar with your research and/or teaching capabilities to:

Professor Robert Hull, Chair

Search Committee for Electronic Materials

Department of Materials Science and Engineering

University of Virginia

Thornton Hall

Chartottesville, VA 22903-2442

Selection of candidates for interview will commence May 31, 1999.

The University of Virginia is an equal opportunity/affirmative action employer

\section{STAFF POSITIONS \\ NZ Applied Technologies}

NZ Applied Technologies, a high-tech INC. 500 company, has several openings in the following areas: ceramic processing, solgel oxide film growth, optical device design, micro-optic packaging, and electronic circuits design. Please send resume to NZAT, HR, 14A Gill Street, Wobum, MA 01801; Fax: 781-935-2188.

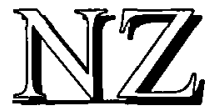

Applied Technologies

For information on marketing opportunities, check the Materials Research Society website: /www.mrs.org/ 


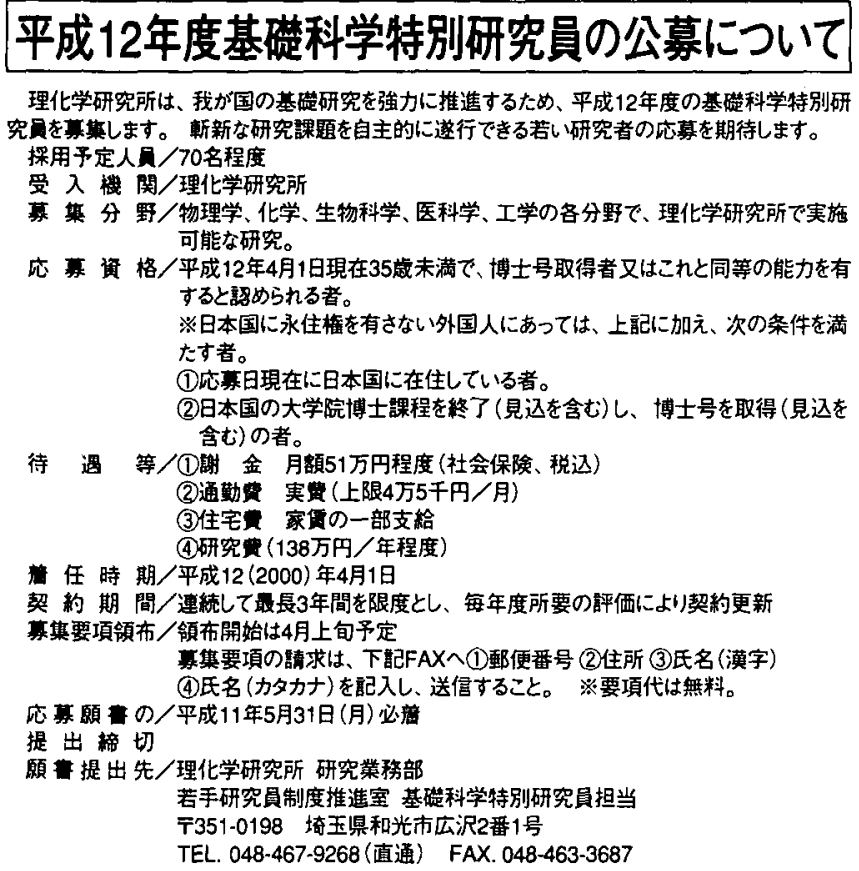

理化学研究所は、我が国の基碳研究を強力に推進するため、平成12年度の基啳科学特別研 究只を严基します。斬新な研究課題を自主的に遂行できる若い研究者の応基を期街します。 採用予定人圆/70名程度

\section{理化学研究所}

\section{RESEARCH SCIENTIST AND ENGINEER POSITIONS Center for Laser \& Photonics Research Oklahoma State University}

We anticipate having junior and senior postdoctoral research scientist positions available in a) MOCVD growth of widegap III-nitride materials; b) processing and fabrication of nitride devices; and c) experimental areas of laser spectroscopy of semiconductor heterostructures. The research involves studies of the optical properties of semiconductors, especially quantum structures, nonlinear optical phenomena, ultrafast carrier dynamics and coherent transients, and growth and processing of semiconductor epilayers and devices. Hands-on experience in nitride MOCVD growth, cleanroom semiconductor processing, or ultrafast femtosecond lasers is desirable.

Successful candidates are expected to contribute to proposal and progress report writing and supervise graduate students, in addition to conducting research. Salary and title are commensurate with experience. Initial appointments are for one year and may be renewed annually. Applicants should apply to PersonnelCode 499 (a, b or c, depending on expertise) by sending vita, list of publications, detailed description of relevant experience, and the name, address, e-mail, and phone number of three or more references to the following:

Betsy Gwyn

Oklahoma State University

Center for Laser \& Photonics Research

413 NRC

Stillwater, OK 74078-3038

Tel: 405-744-6575

Fax: 405-744-6406

E-mail: bld@okway.okstate.edu

Closing date is May 1, 1999 but applications will be accepted beyond that date.

Oklahoma State University is an equal opportunity/affirmative action employer

\section{FACULTY POSITION \\ Future Industry-oriented Basic Science and Materials Division Toyota Technological Institute}

A faculty position is available in the Division of Future Industryoriented Materials at Toyota Technological Institute at the assistant or associate professor level. A doctoral degree in materials or a closely related field is required. The successful candidate will have demonstrated potential to develop strong programs of materials research for information storage such as magnetic and optical recordings. Also, one is expected to excel at teaching in both the graduate and undergraduate programs. Individuals with expertise in materials processing and characterization, as well as those with industrial experience and/or interests in collaborative research with industry, are especially encouraged to apply.

Candidates should send by July 15, 1999 a vitae with a list of publications, a single page summary of research projects and interests, along with the names and addresses of three references to :

Professor Takao Suzuki

Information Storage Materials Research Laboratory

Future Industry-oriented Basic Science and Materials Division

Toyota Technological Institute

2-12-1, Hisakata, Tempaku-ku

Nagoya, $468-8511$

Japan

Tel: $81-52-809-1870$

Fax: 81-52-809-1874

E-mail: tsuzuki@toyota-ti.ac.jp

Toyota Technological Institute is an equal opportunity educational institute and equal opportunity employer.

\section{FACULTY POSITION \\ Biomaterials \\ Georgia Institute of Technology}

The School of Materials Science and Engineering is seeking an Assistant Professor for a tenure-track faculty position to join our dynamic team of internationally recognized faculty, students, staff and alumni, in the areas of biomaterials and biopolymers. A $\mathrm{PhD}$ degree in materials science and engineering or related field is required along with the ability to teach and develop undergraduate and graduate courses in materials, develop a high-quality independent research program, and develop partnerships in research with other members of the faculty.

Please submit a current $\mathrm{CV}$, a letter of application including research interests, copies of three publications, and names and addresses (snail and/or e-mail) of at least three references to:

Dr. Miroslav Marek, Chair

School of Materials Science and Engineering Faculty

Search Committee

Georgia Institute of Technology

Atlanta, GA 30332-0245

Fax: 404-894-2380

E-mail: miroslav.marek@mse.gatech.edu www.mse.gatech.edu/

If an accommodation due to disability is needed to apply for this/these position(s), please indicate accommodations needed in initial correspondence. TDD available upon written request.

An Equal Education/Employment Opportunity Institution

\section{Classified Ads on the Web!} www.mrs.org/bulletin_classifieds/ 


\section{Positions Available}

\section{FACULTY POSITION \\ Department of Materials Science \& Engineering lowa State University}

The Materials Science and Engineering Department at lowa State University is seeking applicants to fill one or more tenure-track faculty positions at the Assistant Professor level. Applications will be accepted in all areas of materials science with special consideration to candidates in metallurgy, polymers, and electronic materials.

Successful candidates must have a PhD degree in materials science or related field. Candidates will be expected to develop and teach undergraduate and graduate courses, as well as to establish and sustain strong sponsored research programs in the area of expertise. Persons with industrial and/or international experience and those with documented teaching experience are encouraged to apply.

The Materials Science and Engineering Department at ISU is one of the leading materials departments in the nation, with 26 faculty members, 85 undergraduate students, and 50 graduate students. Sponsored research expenditures of the department are about $\$ 10 \mathrm{M}$ per year. The department enjoys a close relationship and joint research activities with the Ames Laboratory-USDOE, the Center for Advanced Technology Development, the Center for Nondestructive Evaluation, and the Microelectronics Research Center. Interdisciplinary research is highly encouraged, and the possibility exists for research support from these centers.

Qualified applicants should submit the following: 1) a curriculum vitae, 2) a concise statement of research and teaching interests not to exceed three pages total, and 3) names and addresses of three references to: Chair, Search Committee, Materials Science and Engineering, 3053 Gilman Hall, lowa State University, Ames, lowa 50011.

All applications received by June 15, 1999 will be fully considered. Subsequent applications of an exceptional nature will be accepted until the position is filled.

lowa State University is an Affimative Action/Equal Opportunity Employer

\section{FACULTY POSITIONS IN MATERIALS RESEARCH Institute of Technology University of Minnesota}

The University of Minnesota has created an Initiative on Materials Research. As part of this initiative, five new positions with an interdisciplinary emphasis are to be filled over the next two years. Four are open to candidates with interests in materials synthesis, properties, characterization, and applications. The intent of the positions is to promote strength and collaborations across the Institute of Technology. Areas of particular interest are: magnetoelectronic and magnetic materials, materials for MEMS, organic semiconductors, and electronics and optoelectronics, but the search will consider outstanding candidates in other areas. Departments within the Institute of Technology include Aerospace Engineering and Mechanics, Chemical Engineering and Materials Science, Chemistry, Civil Engineering, Electrical and Computer Engineering, Geology and Geophysics, Mathematics, Mechanical Engineering, and Physics and Astronomy. The candidate's home department will depend on his/her background and research interests. Applicants must possess a strong research record, a demonstrated ability to establish a highly visible research program, and a commitment to teaching and mentoring at the graduate and undergraduate levels. $A P h D$ degree by the time of appointment in a relevant discipline is required. Preference will be given to junior level appointees, but exceptional candidates will be considered for more senior appointments.

The Initiative on Materials Research is part of a broader development program of the University of Minnesota. The recently awarded Materials Research Science and Engineering Center (MRSEC) grant from the National Science Foundation (NSF) together with a number of broader University initiatives will open several new possibilities for collaborative and interdisciplinary research. A Digital Technology Center is being formed with substantial state resources for infrastructure and new faculty. A third area of development involves molecular and cellular biology.

Applicants should submit a curriculum vita, a summary of research accomplishments and plans, a preference of home department, and the names of at least three references to Professor Chris J. Palmstrom, Chair of the Materials Research Search Committee, 151 Amundson Hall, 421 Washington Avenue SE, Minneapolis, MN 55455. For more information, see www.t.umn.edu or e-mail palms001@tc.umn.edu.

Review of applications will begin January 1,1999 . The searches will remain open until the positions are filled.

The University of Minnesota is an equal opportunity educator and employer.

\section{POSTDOCTORAL RESEARCH ASSOCIATES \\ Chemical Vapor Deposition Group University of New Hampshire}

The Chemical Vapor Deposition Group at the University of New Hampshire has two positions for postdoctoral research associates.

Responsibilities:

Investigation of thermal/plasma CVD methods to make nanostructured metal carbide/nitride thin films; characterization of thin films by RBS, XPS, XRD, SEM, and TEM; molecular beam mass spectrometry of plasma CVD to analyze gas-phase chemistry.

Qualifications:

A PhD degree in chemistry, physics, materials science or engineering, or chemical engineering; expertise in gasphase reactions/kinetics, chemically reacting flows, plasma CVD, or mass spectrometry; hands-on experience with HV/UHV technology, computers, and computer software.

Submit a curriculum vitae with three letters of reference to Prof. Carmela Amato-Wierda, Parsons Hall, University of New Hampshire, Dumam, NH 03824.

UNH is committed to enhancing the diversity of its faculty and staff and encourages applications from women, persons of color, persons with disabilities, and veterans.

\section{SCIENTIST}

Brookhaven National Laboratory, under contract with the U.S. Department of Energy, is a multidisciplinary laboratory engaged in a diverse program of basic and applied research.

The Powder Diffraction Group in Solid State Physics is seeking a Scientist of international reputation with a proven track record of innovative research in materials and, condensed matter science to conduct research centered around the application of high-resolution synchrotron $\mathrm{x}$-ray and neutron powder diffraction techniques to structure property relationships in a wide range of materials. Position requires a Ph.D. in materials science, condensed matter physics or chemistry, strong background in crystallography, materials and condensed matter science and the application of powder diffraction techniques, including a detailed knowledge of structure analysis by the Reitveld profile method. Must also have a demonstrated interest in diffraction instrumentation and software for instrument control and data analysis. Under the direction of S. Shapiro.

For consideration. please forward your $C V$ and three letters of reference, indicating position \#MK7656, to: M. Kipperman, Brookhaven National Laboratory, Bidg 185, PO Box 5000 , Upton, NY 11973-5000. For more information about BNL, please visit our website. An equal opportunity employer committed to workforce diversity.

BROOKIIAVEN NATIONAL, I ABORATORY BROOKA AVEN SCIENCE. ASSOCUATR www. bnl.gov 